Original Article

\title{
OPTIMISATION OF IBUPROFEN FAST DISSOLVING TABLETS EMPLOYING STARCH XANTHATE USING $2^{3}$ FACTORIAL DESIGN
}

\author{
R. SANTOSH KUMAR* , T. NAGA SATYA YAGNESH, V. GOUTHAM KUMAR \\ GITAM Institute of Pharmacy, GITAM University, Rushikonda, Visakhapatnam, A. P 530045, India \\ Email: radasantosh@rediffmail.com
}

Received: 05 May 2017, Revised and Accepted: 22 Aug 2017

\begin{abstract}
Objective: To evaluate starch xanthate as a super disintegrant in the formulation of fast dissolving tablets of poorly soluble drugs employing $2^{3}$ factorial design.

Methods: Starch xanthate was synthesized by gelatinization process. The synthesized starch xanthate was subjected to physical and micromeritic evaluation. To establish as starch xanthate as a super disintegrant, fast dissolving tablet of ibuprofen was prepared employing starch xanthate in different proportions in each case by direct compression method employing $2^{3}$ factorial design. All fast dissolving tablets prepared were evaluated for drug content, hardness, friability, disintegration time and other dissolution characteristics like percent dissolved in 5 min (PD $)_{5}$, Dissolution efficiency in 5 Min ( $\left.\mathrm{DE}_{5} \%\right)$ and first order rate constant $\left(\mathrm{K}_{1}\right)$.
\end{abstract}

Results: The starch xanthate prepared was found to be fine, free flowing slightly crystalline powder. Starch xanthate exhibited good swelling in water. Fourier transform infrared spectra (FTIR) and Differential scanning calorimetry (DSC) study indicated the absence of interaction between Ibuprofen and starch xanthate. All the fast dissolving tablets formulated employing starch xanthate were of good quality with regard to drug content $(100 \pm 5 \%)$, hardness $(3.6-4 \mathrm{~kg} / \mathrm{sq} . \mathrm{cm})$, and friability $(0.12-0.15 \%)$. The disintegration time of all the formulated tablets was found to be in the range of $13 \pm 0.02$ to $108 \pm 0.02 \mathrm{~s}$. The optimised formulation FL7 has the least disintegration time i.e., $13 \pm 0$. $02 \mathrm{~s}$. The In vitro wetting time of the formulated tablets was found to be in the range of $90 \pm 0.15$ to $369 \pm 0.17 \mathrm{~s}$. The In-Vitro wetting time was less (i.e., $90 \mathrm{~s}$ ) in optimized formulation FL7. The water absorption ratio of the formulated tablets was found to be in the range of $94 \pm 0.16$ to $192 \pm 0.15 \%$. The cumulative drug dissolved in the optimized formulation FL7 was found to be $99.63 \pm 0.24 \%$ in $5 \mathrm{~min}$.

Conclusion: Starch xanthate was found to be a super disintegrant which enhanced the dissolution efficiency when combined with sodium starch glycolate, croscarmellose sodium, with the ibuprofen and hence it could be used in the formulation of fast dissolving tablets to provide immediate release of the contained drug within $5 \mathrm{~min}$.

Keywords: Optimization, Fast Dissolving, Superdisintegrant

(C) 2017 The Authors. Published by Innovare Academic Sciences Pvt Ltd. This is an open access article under the CC BY license (http://creativecommons.org/licenses/by/4.0/) DOI: http://dx.doi.org/10.22159/ijap.2017v9i5.19707

\section{INTRODUCTION}

Oral routes of drug administration have wide acceptance up to 50$60 \%$ of the total dosage form. Fast dissolving tablets (FDT) are solid dosage form containing indicated substances which disintegrate rapidly, usually within few seconds when placed upon tongue requiring additional water to facilitate swallowing [1]. Fast dissolving tablets offer great advantages for the patients having difficulty in swallowing [2]. The elderly constitute a major portion of today's population mainly because of the increased life span of individuals. Physiological and neurological conditions, such as dysphasia, a risk of choking, and hand tremors are leading causes of patient non-compliance in the self-administration of conventional solid oral dosage forms. Fast dissolving tablets overcome this problem and provide the advantages for paediatrics, geriatric [3], bedridden, disabled patients and also for who may have difficulty in swallowing tablets, capsules, and liquid orals. FDT will rapidly disintegrate in the mouth without the need of water [4-5]. Fast dissolving tablet formulation provides sufficient strength, quick disintegration/dissolution in the mouth without water [6], rapid dissolution and absorption of the drug, which will produce the quick onset of action. Pre gastric absorption of fast dissolving tablets can result in improved bioavailability and as a consequence of reduced dose [7]. Various techniques can be used to formulate fast dissolving tablets. Direct compression one of the techniques which require the incorporation of super disintegrant or highly water-soluble excipients into the formulation to achieve fast tablet disintegration. Direct compression does not require the use of water or heat during the formulation procedure and is the ideal method for moisture and heat-liable medication. The aim of the work was to formulate and characterize fast-dissolving tablets of ibuprofen by utilizing optimization techniques for rapid dissolution of drug and absorption employing a new super disintegrant i.e., starch xanthate.
Optimization technique provides both depth of understanding and an ability to explore and define ranges for formulation and processing factors with a rational approach to the selection of several experimental and manufacturing step for a given product, to quantitatively select a formulation. It is at this point that optimization can become a useful tool to quantitative a formulation that has been qualitatively determined.

The present investigation deals with an attempt of systematic formulation approach for optimization of ibuprofen fast dissolving tablets employing starch xanthate, sodium starch glycolate, croscarmellose sodium as super disintegrants. A $2^{3}$ factorial design was applied to investigation the main and interaction effects of the three formulation variables i.e., starch xanthate (A), sodium starch glycolate (B), croscarmellose sodium (C) in each case to find the formula with less disintegration time and more dissolution efficiency $5 \mathrm{~min}$ and to permit arbitrary selection of tablets with immediate release of drug with in $5 \mathrm{~min}$.

\section{MATERIALS AND METHODS}

\section{Materials}

Sodium hydroxide, Carbon disulfide, Lactose was purchased from Finar chemicals Ltd, Ahmedabad. Potato starch, Ibuprofen, Sodium starch glycolate, Croscarmellose sodium was obtained from Yarrow chem. Products, Mumbai. Microcrystalline cellulose was bought from Qualigens fine chemicals, Mumbai. Talc and Magnesium stearate was obtained from Molychem, Mumbai.

Preparation of starch xanthate (a novel Superdisintegrant)

Initially, 35.4 parts of potato starch were slurried in $225 \mathrm{ml}$ distilled water and 8 parts of sodium hydroxide was dissolved in 
distilled water. Both are stirred continuously for $30 \mathrm{~min}$. To this 5 parts of carbon disulphide was added and stirred for $16 \mathrm{~h}$ at 25 ${ }^{\circ} \mathrm{C}$. After $16 \mathrm{~h}$, it was filtered and washed with $75 \mathrm{ml}$ of distilled water, $500 \mathrm{ml}$ of acetone and $100 \mathrm{ml}$ of ether. The product was kept in an oven at $60{ }^{\circ} \mathrm{C}$ for $2 \mathrm{~h}$. The product obtained was ground and sieved.

\section{Characterization of starch xanthate}

The starch xanthate prepared was evaluated for the following

\section{Solubility}

The solubility of starch xanthate was tested in water, an aqueous

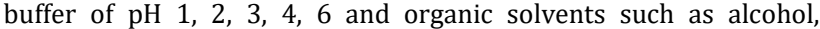
dichloromethane, chloroform, acetone and petroleum ether.

\section{pH}

The $\mathrm{pH}$ of $1 \% \mathrm{w} / \mathrm{v}$ slurry was measured by $\mathrm{pH}$ meter.

\section{Melting point}

Melting point was determined by using melting point apparatus.

\section{Viscosity}

The viscosity of $1 \%$ dispersion in water was measured using Ostwald viscometer.

\section{Swelling index}

Starch xanthate $(200 \mathrm{mg})$ was added to $10 \mathrm{ml}$ of water and light liquid paraffin taken in two Different graduated test tubes and mixed. The dispersion in the tubes was allowed to stand for $12 \mathrm{~h}$. The volumes of the sediment in the tubes were recorded. The swelling index of the material was calculated as follows.

$$
\text { SwellingIndex } \%=\frac{\text { VolumeofSedimentinwater-VolumeofsedimentinLighLiquidPardfin }}{\text { VolumeofSedimentinLighLiquidPardfin }} X 100
$$

\section{Test for gelling property}

The gelling property (gelatinization) of the starch and starch xanthate prepared was evaluated by heating a $7 \% \mathrm{w} / \mathrm{v}$ dispersion of each in water at $100^{\circ} \mathrm{C}$ for $30 \mathrm{~min}$.

\section{Particle size}

Particle size analysis was done by sieving using standard sieves.

\section{Density}

Density (g/cc) was determined by liquid displacement method using benzene as a liquid.

\section{Bulk density}

Both loose bulk density (LBD) and tapped bulk density (TBD) were determined by transferring the accurately weighed amount of sample in $50 \mathrm{ml}$ measuring cylinder, the granules without any agglomerates and measured the volume of packing and tapped 50 times on a plane surface and tapped volume of packing recorded and LBD and TBD calculated by following formula [8].

$$
\begin{gathered}
L B D=\frac{\text { Massofpowder }}{\text { Volumeofpacking }} \\
T B D=\frac{\text { Massofpowder }}{\text { TappedVolumeofPacking }}
\end{gathered}
$$

\section{Percentage compressibility index}

Percentage compressibility of powder mix was determined by Carr's Compressibility Index calculated by the following formula [9].

$$
\% \text { Carr ' sIndex }=\frac{T B D-L B D}{T B D} \times 100
$$

Where TBD= Tapped bulk density; $\mathrm{LBD}=$ Loose bulk density.

\section{Angle of repose}

The frictional forces in loose powder or granules can be measured by the angle of repose. This is the maximum angle possible between the surface of a mass of powder or granules and the horizontal plane. Angle of repose is calculated by applying the next equation;

$$
\tan \theta=\frac{h}{r}, \theta=\tan ^{-1} \frac{h}{r}
$$

Where $\theta=$ angle of repose; $h=$ height; $r=$ radius

\section{Fourier transform infrared (FTIR) spectroscopy}

FTIR spectra of starch lactate were recorded on samples prepared in potassium bromide (KBr) disks using a BRUKER FT-IR, (Tokyo, Japan). Samples were prepared in $(\mathrm{KBr})$ disks by means of a hydrostatic press at 6-8 tons pressure. The scanning range was 500 to $4000 \mathrm{~cm}^{-1}$.

\section{X-Ray diffraction}

The diffraction pattern of starch xanthate was recorded with an $\mathrm{x}$ ray diffractometer (analytical spectra's Pvt. Ltd., Singapore). X-ray diffraction was performed at room temperature $\left(30^{\circ} \mathrm{C}\right)$ with a diffractometer; target, $\mathrm{Cu}(\lambda 1.54 \mathrm{~A})$, filter, $\mathrm{Ni}$; voltage, $40 \mathrm{kV}$; current $30 \mathrm{~mA}$; time constant $10 \mathrm{~mm} / \mathrm{s}$; scanning rate $2 \%$ min; measured from $2.5-50^{\circ}$ at full scale 200 .

\section{Drug-excipients compatibility studies}

The compatibility of starch xanthate with the selected drug (Ibuprofen) was evaluated in DSC and FTIR studies.

\section{Differential scanning calorimetry (DSC)}

DSC thermograms of ibuprofen and their mixtures (1: 1) with starch xanthate were recorded on Perkin-Elmer thermal analyzer samples (2-5 $\mathrm{mg})$ were sealed into aluminum pans and scanned at a heating rate of $10^{\circ} \mathrm{C} \mathrm{min}-1$ over a temperature range $30-350{ }^{\circ} \mathrm{C}$.

\section{Infrared spectroscopy}

Fourier transform infra red (FTIR) spectra of ibuprofen, and their mixtures (1:1) with starch xanthate were recorded on a Perkin-Elmer, IR Spectrophotometer model: Spectrum RXI, using $\mathrm{KBr}$ disc as a reference.

\section{Preparation of ibuprofen fast dissolving tablets}

The tablets were prepared by direct compression method employing $2^{3}$ factorial design in which 3 independent variables ssuperdisintegrants i.e., starch xanthate (A), sodium starch glycolate (B), croscarmellose sodium (C)\} and 1 dependent variable (dissolution efficiency in $5 \mathrm{~min}$ ) were selected. The composition of the different formulation of ibuprofen fast dissolving tablets is shown in table no 1 in which the levels of super disintegrants were selected at 2 levels i.e., lower and higher level concentrations. For starch xanthate (A), the lower level i.e., 5\% concentration and upper level i.e., $10 \%$ concentration. For sodium starch glycolate (B) and croscarmellose sodium(C), the lower level is 0 concentration and higher level i.e., $5 \%$ concentration. For uniformity in particle size each ingredient was passed through \# 100 mesh sized screen before mixing. Starch xanthate, sodium starch glycolate, croscarmellose sodium, mannitol and microcrystalline cellulose were accurately weighed and mixed using mortar and pestle, and the added to ibuprofen. Finally, talc and magnesium stearate were added to the powder mixture. Finally, the mixed blend was compressed by using eight station rotator press Karnawathi Machineries Pvt, Ltd., Ahmedabad, India.

\section{Evaluation of ibuprofen fast dissolving tablets}

\section{Hardness test}

Hardness indicates the ability of a tablet to withstand mechanical shocks while handling. The hardness of the tablet was determined using Monsanto hardness tester and expressed in $\mathrm{kg} / \mathrm{cm}^{2}[10]$.

\section{Uniformity of weight}

Weight variation test was done with 20 tablets. It is the individual variation of tablet weighed from the average weight of 20 tablets [11]. 
Table 1: Formulae of ibuprofen fast dissolving tablets employing starch xanthate prepared by direct compression method involving lactose as a diluent

\begin{tabular}{|c|c|c|c|c|c|c|c|c|}
\hline Ingredients (mg/tablet) & FL1 & FL2 & FL3 & FL4 & FL5 & FL6 & FL7 & FL8 \\
\hline Ibuprofen & 100 & 100 & 100 & 100 & 100 & 100 & 100 & 100 \\
\hline Starch Xanthate & 25 & 50 & 25 & 50 & 25 & 50 & 25 & 50 \\
\hline Sodium starch glycolate & --- & -- & 25 & 25 & --- & --- & 25 & 25 \\
\hline Croscarmellose sodium & --- & --- & --- & --- & 25 & 25 & 25 & 25 \\
\hline Lactose & 155 & 130 & 130 & 105 & 130 & 105 & 105 & 80 \\
\hline Micro crystalline cellulose & 200 & 200 & 200 & 200 & 200 & 200 & 200 & 200 \\
\hline Talc & 10 & 10 & 10 & 10 & 10 & 10 & 10 & 10 \\
\hline Magnesium state & 10 & 10 & 10 & 10 & 10 & 10 & 10 & 10 \\
\hline Total & 500 & 500 & 500 & 500 & 500 & 500 & 500 & 500 \\
\hline
\end{tabular}

Table 2: Physical and micromeritics properties of the starch xanthate prepared

\begin{tabular}{ll}
\hline Parameters* & Observation \\
\hline Solubility & Insoluble in all aqueous and organic solvents tested \\
pH(1\% w/v aqueous dispersion) & 6.194 \\
Melting point & Charred at $218^{\circ} \mathrm{C}$ \\
Viscosity $(1 \% \mathrm{w} / \mathrm{v}$ aqueous & $1.016 \mathrm{cps}$ \\
dispersion) & $50 \%$ \\
Swelling index & No gelling and the swollen particles of starch Xanthate separated from water. Where as in the case of starch, it \\
Gelling property & was gelatinized and formed a gel. \\
& $80 \mu \mathrm{m}(80 / 120$ mesh) \\
Particle Size & $0.9848 \mathrm{~g} / \mathrm{cc}$ \\
Density & $0.625 \mathrm{~g} / \mathrm{cc}$ \\
Bulk density & $12.4{ }^{\circ}$ \\
Angle of repose & $32.5 \%$ \\
Compressibility index &
\end{tabular}

*SD Standard Deviation from mean, $\mathrm{n}=3$

\section{Friability}

The friability of tablets was measured using a Roche fribilator. Tablets were rotated at $25 \mathrm{rpm}$ for $4 \mathrm{~min}$ or up to 100 revolutions. The tablets were then reweighed after removal of fines and the percentage of weight loss was calculated [11].

$$
F=\frac{W(\text { initial })-W(\text { final })}{W(\text { initial })} X 100
$$

\section{Drug content uniformity}

For content uniformity, ten tablets were weighed and powdered a quantity of powder equivalent to $10 \mathrm{mg}$ of ibuprofen was extracted into 7.2 phosphate buffer and filtered. The Ibuprofen content was determined by measuring the absorbance spectrophotometrically at $254 \mathrm{~nm}$ after appropriate dilution with 7.2 phosphate buffer. The drug content was calculated as an average of three determinations [11].

\section{Wetting time}

The wetting time of tablets was measured using a very simple procedure five circular tissue papers of $10 \mathrm{~cm}$ diameter were placed in a Petri dish with a $10 \mathrm{~cm}$ diameter. Ten $\mathrm{ml}$ of water containing a water-soluble dye (amaranth) was added to the petri dish. A tablet was carefully placed on the tissue paper. Time required for water to reach the upper surface of the tablet was noted as wetting time $[12,13]$

\section{Water absorption ratio}

A piece of tissue paper folded twice in a small petri dish containing 6 $\mathrm{ml}$ of water. A tablet was put in the tissue paper allowed to completely wet. The wetted tablet was then weighed. Water absorption ration $\mathrm{R}$ was determined using following equation $[12,13]$.

$$
R=\frac{W_{a}-W_{b}}{W_{b}} X 100
$$

Where,

$\mathrm{W}_{\mathrm{a}}=$ weight of tablet after water absorption.

$\mathrm{W}_{\mathrm{b}}=$ weight of tablet before water absorption.

\section{In-vitro disintegration time}

Disintegration time for FDTs was determined using USP disintegration apparatus $0.1 \mathrm{~N} \mathrm{HCl}$ buffer. The volume of medium was $900 \mathrm{ml}$ and the temperature was $37 \pm 0.2{ }^{\circ} \mathrm{C}$. The time in second taken for complete disintegration of the tablet with no palatable mass remaining in the apparatus was measured [14].

\section{In-vitro dissolution studies}

The in vitro dissolution rate study of ibuprofen fast dissolving tablets were performed using 8 stage dissolution test apparatus (Electrolab TDT-08L) fitted with paddles (50 rpm) at $37 \pm 0.5{ }^{\circ} \mathrm{C}$, using 7.2 phosphate buffer $(900 \mathrm{ml})$ as a dissolution media. At the predetermined time intervals, $5 \mathrm{ml}$ samples were withdrawn, filtered through a $0.45 \mu$ membrane filter, diluted and assayed at 221 $\mathrm{nm}$ using an Analytical technology T360 UV/Visible Double beam spectrophotometer. Cumulative percentage release was calculated using standard absorbance from the calibration curve. All the dissolution experiments were conducted in triplicate $(n=3)$.

\section{RESULTS AND DISCUSSION}

The starch xanthate prepared was found to be fine, free flowing slightly crystalline powder. Therefore, starch xanthate can be used in the formulation of fast dissolving tablets. The physical and micro-meritics properties of the starch xanthate are summarized in table 2. It was insoluble in aqueous solvents and insoluble in organic solvents tested (methanol, petroleum ether, dichloromethane, and chloroform) and the $\mathrm{pH}$ of $0.1 \%$ aqueous dispersion was 6.196 which is suitable in the formulation of fast dissolving tablets.

Starch xanthate exhibited good swelling in water. The swelling index of starch xanthate was found to be $50 \%$, indicating that the starch xanthate can swell and can increase the osmotic pressure inside the fast dissolving tablets upon oral administration leading to the quick disintegration of the fast dissolving tablets. All micrometric properties indicated good flow and compressibility needed for solid dosage form manufacturing. The density of starch xanthate was found to be $0.9848 \mathrm{~g} / \mathrm{cc}$. 
The angle of repose and compressibility index showed good flow properties of starch xanthate. The FTIR spectrum of potato starch and starch xanthate is shown in fig. 1 and 2 . The presence of peaks absorption at $1634.10 \mathrm{~cm}^{-1}$ characteristic peaks of ester, so from FTIR studies it was concluded that starch xanthate (ester) was formed when starch was allowed to react with formic acid. The X-ray diffraction pattern (fig. 3) of starch xanthate showed characteristic peaks, which indicates that the structure is slightly crystalline in nature suitable for as super disintegrant in the formulation of fast dissolving tablets. The disappearance of pink color in the ester test confirmed the presence of ester, i.e., starch xanthate.
The melting point of starch xanthate was found to be $218^{\circ} \mathrm{C}$, which can resist the higher temperature during drying when used in the wet granulation method of preparation of tablets and also during accelerated stability studies. The viscosity of $1 \% \mathrm{~W} / \mathrm{V}$ aqueous dispersion of starch xanthate was found to be $1.016 \mathrm{cps}$ indicating the suitability of starch xanthate as a super disintegrant in the formulation of the fast dissolving tablets with less disintegration time. The particle size of starch xanthate was found to be $80 \mu$ indicating the suitability of starch xanthate as a free flowing super disintegrant in the formulation of fast dissolving tablets. The starch xanthate had got all the characteristic of super disintegrants it was concluded that starch xanthate can be used as novel super disintegrant in the formulation of fast dissolving tablets.

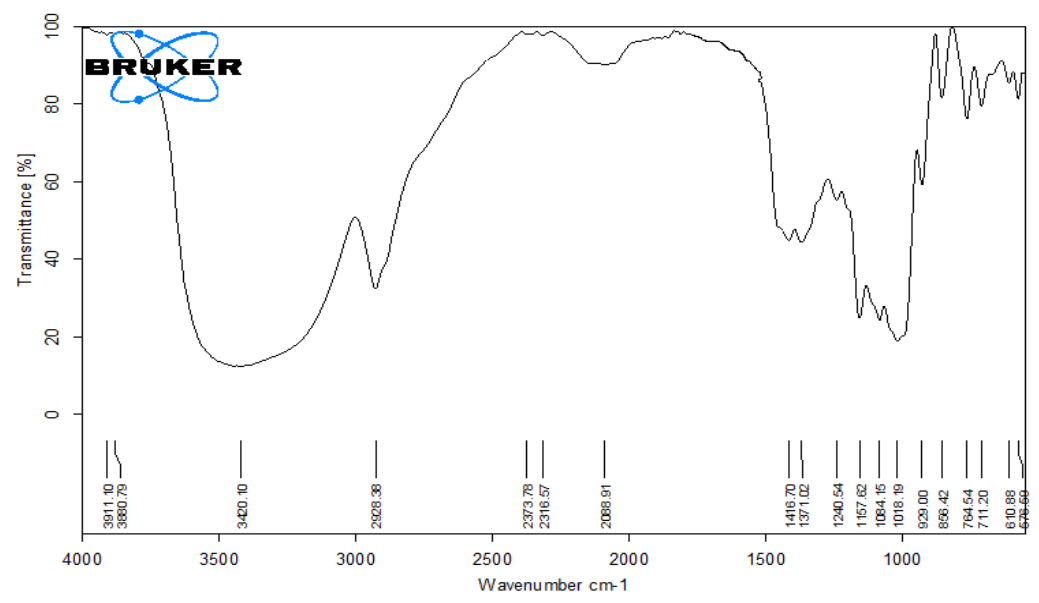

Fig. 1: Fourier transform infrared spectra of potato starch

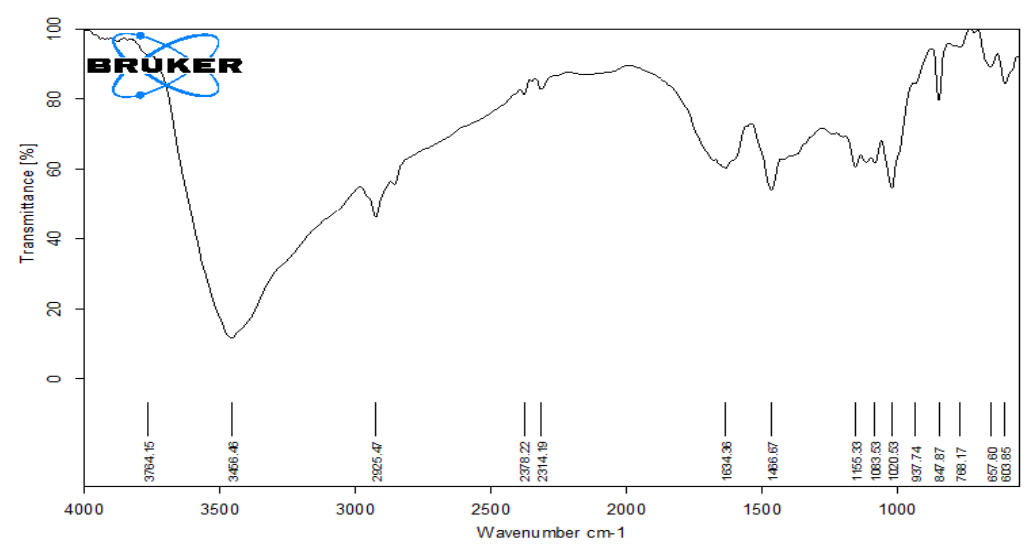

\begin{tabular}{lll}
\hline Sample & Frequency of peak & Functional group \\
\hline Starch xanthate & 1634.36 & $(-\mathrm{COOH})$ \\
\hline
\end{tabular}

Fig. 2: Fourier transform infrared spectra of starch xanthate

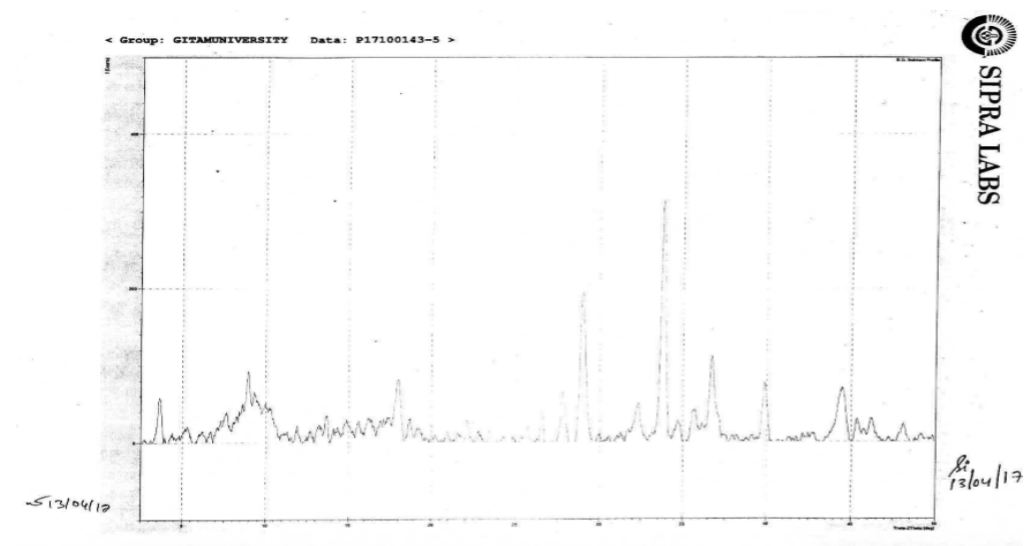

Fig. 3: X-Ray diffraction pattern of starch xanthate 
The X-ray diffraction pattern of starch xanthate showed 3 characteristic peaks, which indicates that structure is slightly crystalline. The compatibility of starch xanthate with the selected drug (Ibuprofen) was evaluated by DSC and FTIR studies. The DSC thermograms of ibuprofen and ibuprofen-starch xanthate are shown in fig. 4 and 5. The DSC thermograms of ibuprofen and ibuprofen-starch xanthate exhibited exothermic peaks at $83.34{ }^{\circ} \mathrm{C}$ and $63.13{ }^{\circ} \mathrm{C}$ respectively. These melting peaks of ibuprofen and ibuprofen-starch xanthate are nearer to the melting points of ibuprofen $\left(75-78^{\circ} \mathrm{C}\right)$. The peaks observed in the DSC thermograms of ibuprofen and ibuprofen-starch xanthate mixtures correspond to the melting points of the respective drug indicating no interactions between the selected drug and starch xanthate polymer. The DSC study, thus, indicated no interaction between starch xanthate and selected drug.

The FTIR spectra of ibuprofen and ibuprofen-starch xanthate are shown in fig. 6 and 7. The characteristic FTIR bands of ibuprofen at $1718.78 \mathrm{~cm}$ ${ }^{1}(\mathrm{COOH})$, and ibuprofen-starch xanthate at $1716.17 \mathrm{~cm}^{-1}(\mathrm{COOH})$ were all observed in the FTIR spectra of both ibuprofen and ibuprofen-starch xanthate. These FTIR spectra observations also indicated no interaction between starch xanthate and the drug selected.

Thus the result of DSC and FTIR indicated no interaction between the selected drug and starch xanthate, the new super disintegrant. Hence starch xanthate could be used as a super disintegrant in the design of fast dissolving tablets of the selected drug.

\begin{tabular}{lll}
\hline & Temperature ${ }^{\circ} \mathrm{C}$ & Peak \\
\hline Sample & Onset & \\
\hline Ibuprofen & $76.31^{\circ} \mathrm{C}$ & $83.34{ }^{\circ} \mathrm{C}$ \\
\hline
\end{tabular}

Fig. 4: DSC Thermogram of ibuprofen pure drug

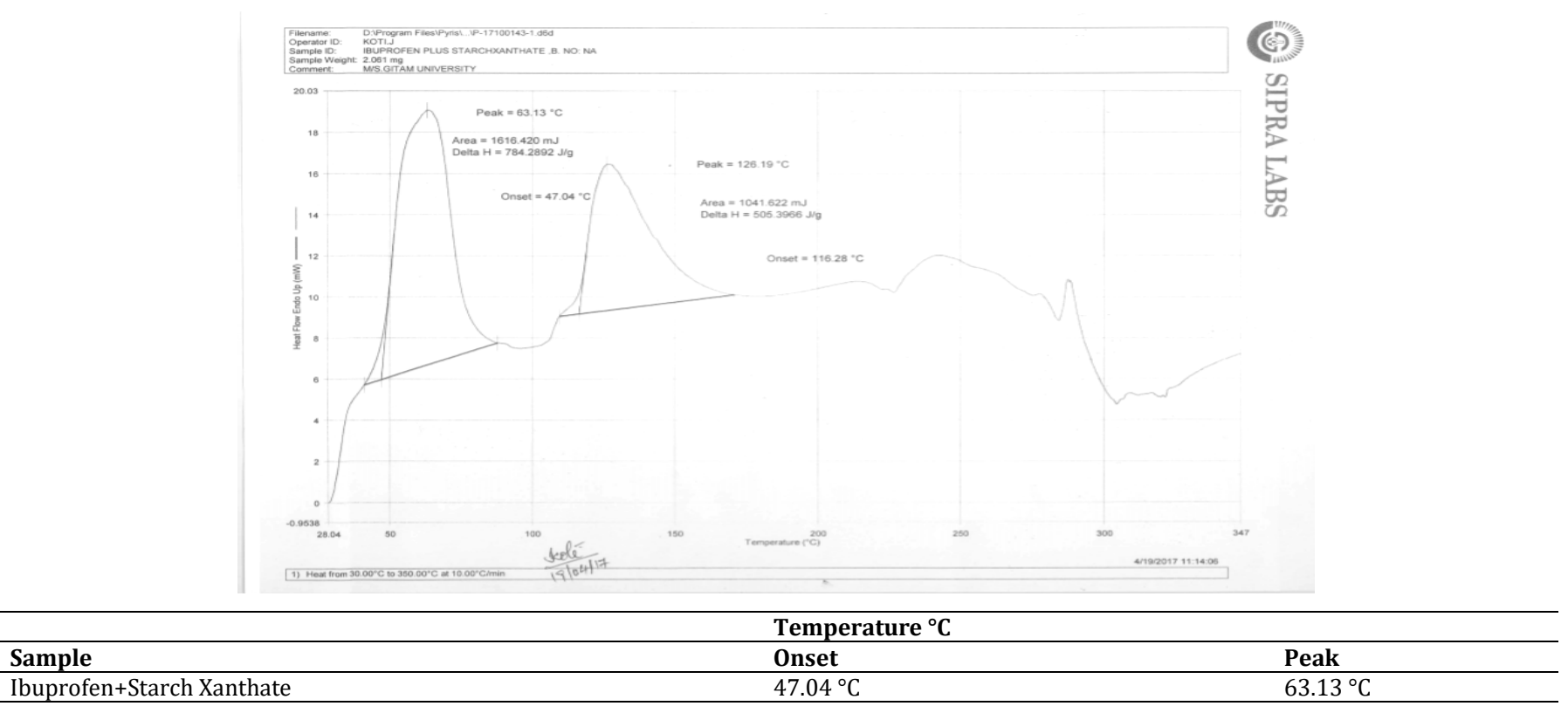

Fig. 5: DSC Thermo gram of ibuprofen with starch xanthate

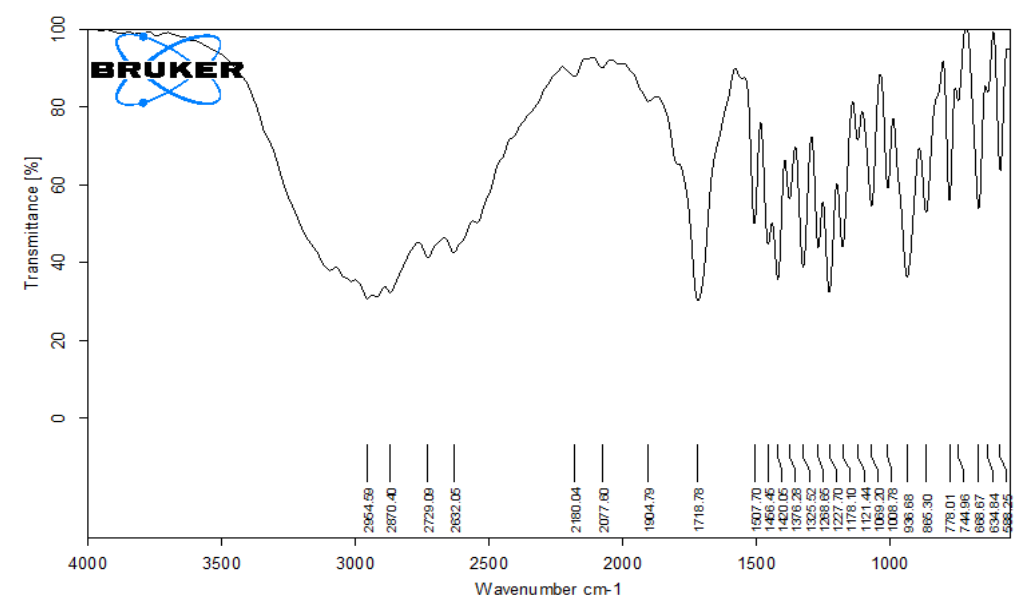

\begin{tabular}{lll}
\hline Sample & Frequency of peak & Functional group \\
\hline Ibuprofen & 1718.78 & $(-\mathrm{COOH})$ \\
\hline
\end{tabular}

Fig. 6: FTIR spectra of ibuprofen 


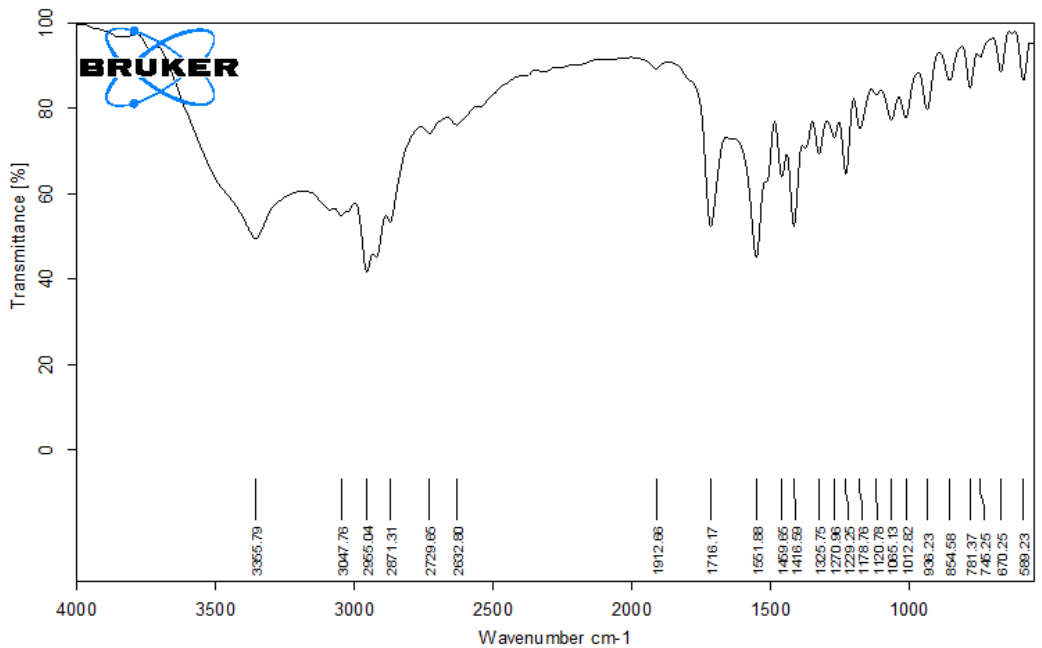

\begin{tabular}{lll}
\hline Sample & Frequency of peak & Functional group \\
\hline Ibuprofen+Starch Xanthate & 1716.17 & $(-\mathrm{COOH})$ \\
\hline
\end{tabular}

Fig. 7: FTIR spectra of ibuprofen with starch xanthate

\section{Evaluation of tablets}

\section{Hardness}

Hardness of tablets from all batches was found to be in the range of $3.6 \pm 0.03 \mathrm{~kg} / \mathrm{cm}^{2}$ to $4 \pm 0.01 \mathrm{~kg} / \mathrm{cm}^{2}$. All tablets were found hard enough so that they could easily withstand the handling and storage conditions without getting broken.

\section{Friability}

All the tablets exhibited acceptable friability as none of the tested batches showed percentage friability that exceeded $1 \%$. As per IP, $\%$ friability below $1 \%$ is an indication of good mechanical resistance of the tablets. \% friability of all batches found in the range of $0.12 \%$ $0.15 \%$. Thus, it was proved that tablets could withstand the pressure, mechanical shocks during handling, transportation, storage and manufacturing processes.

\section{Drug content}

Drug content of all the formulation batches was found to be between $97.58 \pm 0.71$ to $99.56 \pm 0.57$. Hence, it can be concluded that all the formulations are having an accurate amount of drug distributed uniformly in powder mass and followed acceptable limits as per IP [15]. i.e. 85 to $115 \%$ of average content table 3 .

\section{Disintegration studies}

In vitro disintegration time was done by the USP dissolution apparatus. The disintegration rate has a correlation with water absorption capacity of disintegrate and The In vitro disintegration time was found between $178 \pm 0.02-13 \pm 0$. 01s. The outcomes were tabulated and data demonstrated in table 3. All the formulation showed disintegration time less than $180 \mathrm{~s}$. It was found that the formulation Fl7 will show least disintegration time 13s as compare to other formulation. The order for a disintegration time in fast dissolving tablet was found to be FL7<FL3<FL4<FL5 $<$ FL $6<$ FL $2<$ FL1 $<$ FL8. The order of disintegration time may be due to the interaction and main effects of the super disintegrants used in the fast dissolving tablets.

\section{Water absorption ratio and wetting time}

The Water absorption ratio founded between $94 \pm 0.16-192 \pm 0.15$. This increased behaviour due to the water taking the ability of super disintegrants. The wetting time found between $90 \pm 0.15-369 \pm 0.17$. The outcomes were tabulated and data demonstrated in table 3 and Fig. 8 and 8a. It was found that the formulation FL7 containing $5 \%$ starch xanthate, $5 \%$ sodium starch glycolate and $5 \%$ croscarmellose sodium showed less wetting time i.e. $90 \pm 0.15 \mathrm{~s}$ as compared to other formulations.

\section{In vitro dissolution studies}

Dissolution rate depends on the wetting time of the disintegrant, among all the formulations FL7 has less wetting time and has greater dissolution rate and then this is the other conformance test for correct selection of desirable. In vitro dissolution studies of all the formulation were done and depicted in fig. 9. In all formulations FL7 formulation was selected as the promising formulation containing $5 \%$ starch xanthate, $5 \%$ sodium starch glycolate and $5 \%$ croscarmellose sodium with $99.30 \%$ release in 5 min which may be due to the interaction effect between the three super disintegrants i.e., starch xanthate, sodium starch glycolate and croscarmellose sodium at a concentration of $5 \%$ each.

The dissolution parameters of the formulation from (FL1-FL8) which were made by direct compression method were shown in the Table: 4. In all these cases the $\mathrm{PD}_{5}$ (percent dissolved in $5 \mathrm{~min}$ ) was more (99.63) in FL7 which consists at $5 \%$ starch xanthate, $5 \%$ sodium starch glycolate and $5 \%$ croscarmellose sodium. The same was in the case of $\mathrm{DE}_{5} \%$ (dissolution efficiency in $5 \mathrm{~min}$ ). The $\mathrm{PD}_{5}$ and $\mathrm{DE}_{5} \%$ revels that starch xanthate was effective at $5 \%$ starch xanthate, $5 \%$ sodium starch glycolate, and $5 \%$ croscarmellose sodium when the formulations were made by direct compression using these super disintegrants. The order for a $\mathrm{PD}_{5}$ in fast dissolving tablet was found to be FL1 $<$ FL2 $<$ FL4 $<$ FL8 $<$ FL6 $<$ FL5 $<$ FL3 $<$ FL7 . The $\mathrm{K}_{1}$ also increased in all the formulation when compared to the $\mathrm{F} 1$ formulation. The number of folds increases in $\mathrm{DE}_{5} \%$ and the number of folds increase in $\mathrm{K}_{1}\left(\mathrm{~min}^{-1}\right)$ was given in table 4 . The order for a DE5\% in fast dissolving tablet was found to be FL $8<$ FL $1<$ FL $2<$ FL4 $<$ FL $6<$ FL $5<$ FL $3<$ FL7 . The order of $\mathrm{PD}_{5}$ and $\mathrm{DE}_{5} \%$ may be due to the interaction and main effects of the super disintegrants used in the fast dissolving tablets. From the results, it was concluded that starch xanthate (new super disintegrant) could be used as a super disintegrant in the formulation of fast dissolving tablets of ibuprofen.

To evaluate the individual and combined effects of the three factors involved, fast dissolving tablets were formulated employing selected combinations of the factors as per $2^{3}$-factorial design. The fast dissolving tablets and release parameters (percent drug released in $5 \mathrm{~min}$ ) of the fast dissolving formulated were analyzed as per ANOVA of $2^{3}$-factorial design. ANOVA of fast disintegrating times (table 5) indicated that the individual effects of starch xanthate (A), sodium starch glycolate (B) and croscarmellose sodium (C), as well as the combined effects of $\mathrm{AB}, \mathrm{AC}, \mathrm{BC}$ and $\mathrm{ABC}$ factors, were 
significant $(\mathrm{P}<0.05)$ on disintegration time and dissolution efficiency in $5 \mathrm{~min}$ of ibuprofen fast dissolving tablets.

Fast dissolving tablets formulated employing starch xanthate (5\%), sodium starch glycolate (5\%) and croscarmellose sodium (5\%) as super disintegrants exhibited in disintegration and dissolution efficiency in 5 min. Formulation FL7 gave release of $99.63 \%$ in 5 min fulfilling the official specification, based on disintegration time and dissolution efficiency in 5 min. Formulation FL7 is considered as a good fast dissolving tablet formulations of ibuprofen which was found to better than the ibuprofen fast dissolving tablets formulated by Sai Kishore et al [16].

Table 3: Physical properties: hardness, friability drug content of ibuprofen fast dissolving tablets prepared by direct compression method involving lactose as a diluent

\begin{tabular}{|c|c|c|c|c|c|c|}
\hline Formulation & $\begin{array}{l}\text { Hardness } \\
\left(\mathrm{kg} / \mathrm{cm}^{2}\right) \mathrm{n} \pm S D\end{array}$ & $\begin{array}{l}\text { Friability } \\
(\%) n \pm \text { SD }\end{array}$ & $\begin{array}{l}\text { Drug Content } \\
\mathrm{mg} / \mathrm{tab}) \mathrm{n} \pm S D\end{array}$ & $\begin{array}{l}\text { Disintegration Time } \\
\text { (sec) } n \pm S D\end{array}$ & $\begin{array}{l}\text { Wetting Time } \\
\text { (s) } n \pm S D\end{array}$ & $\begin{array}{l}\text { Water Absorption } \\
\text { Ratio (\%) } n \pm \text { SD }\end{array}$ \\
\hline FL1 & $3.9 \pm 0.01$ & $0.12 \pm 0.013$ & $97.58 \pm 0.71$ & $108 \pm 0.02$ & $310 \pm 0.02$ & $145 \pm 0.12$ \\
\hline FL2 & $3.6 \pm 0.03$ & $0.13 \pm 0.015$ & $98.10 \pm 0.79$ & $103 \pm 0.03$ & $276 \pm 0.12$ & $137 \pm 0.18$ \\
\hline FL3 & $4.0 \pm 0.01$ & $0.14 \pm 0.012$ & $99.45 \pm 0.63$ & $14 \pm 0.02$ & $111 \pm 0.09$ & $94 \pm 0.16$ \\
\hline FL4 & $3.8 \pm 0.04$ & $0.12 \pm 0.014$ & $98.56 \pm 0.55$ & $25 \pm 0.02$ & $225 \pm 0.02$ & $134 \pm 0.15$ \\
\hline FL5 & $3.7 \pm 0.03$ & $0.14 \pm 0.012$ & $99.23 \pm 0.56$ & $83 \pm 0.01$ & $103 \pm 0.21$ & $139 \pm 0.21$ \\
\hline FL6 & $3.9 \pm 0.01$ & $0.15 \pm 0.012$ & $99.34 \pm 0.18$ & $95 \pm 0.02$ & $183 \pm 0.09$ & $111 \pm 0.12$ \\
\hline FL7 & $3.7 \pm 0.02$ & $0.14 \pm 0.014$ & $99.56 \pm 0.57$ & $13 \pm 0.01$ & $90 \pm 0.15$ & $192 \pm 0.15$ \\
\hline FL8 & $4.0 \pm 0.04$ & $0.12 \pm 0.013$ & $99.17 \pm 0.11$ & $178 \pm 0.02$ & $369 \pm 0.17$ & $126 \pm 0.27$ \\
\hline
\end{tabular}

*SD Standard Deviation from mean, $\mathrm{n}=3$

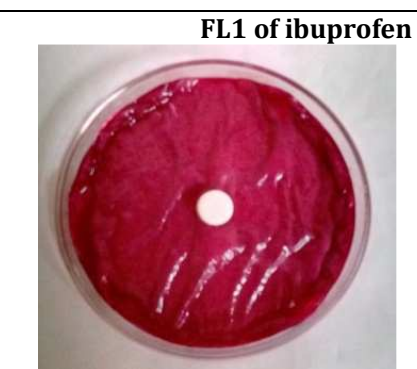

At Time $=0$ sec

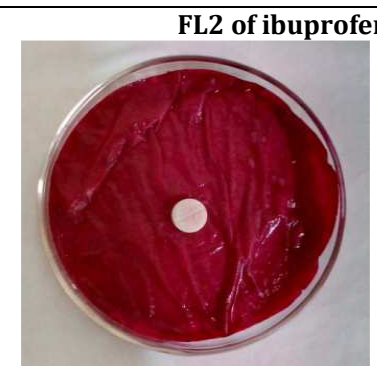

At Time $=0$ sec

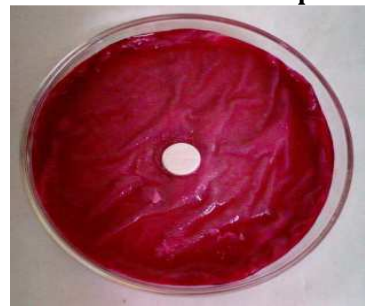

At Time $=0$ sec

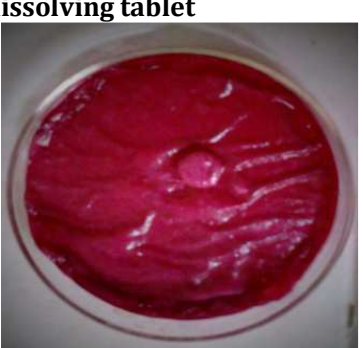

At Time $=111 \mathrm{sec}$

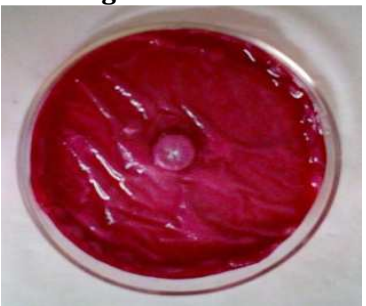

At Time $=111 \mathrm{sec}$

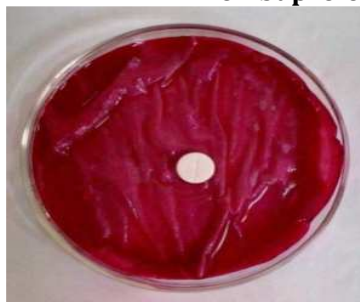

At Time $=0$ sec

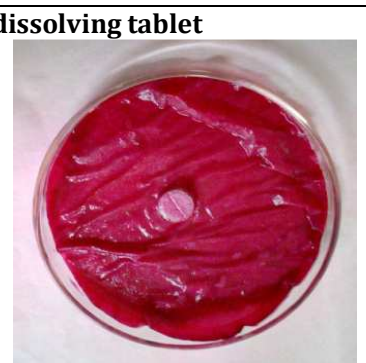

At Time $=276 \mathrm{sec}$

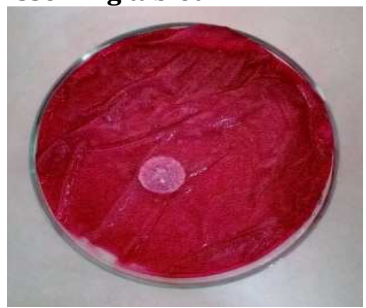

At Time $=225$ sec

Fig. 8: Ibuprofen fast dissolving tablets prepared employing starch xanthate involving lactose as a diluent

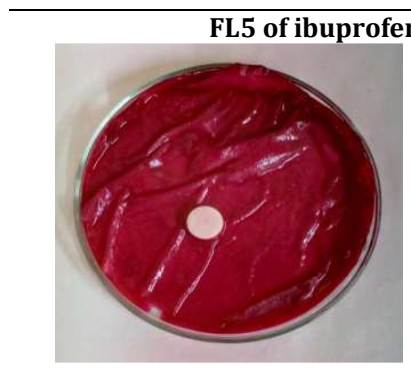

At Time $=0$ sec

FL7 of ibuprofen fast dissolving tablet

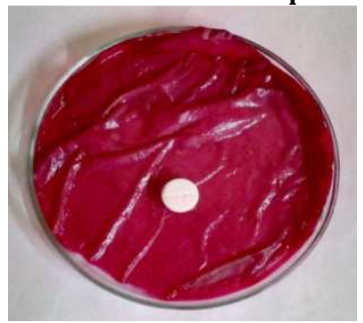

At Time $=0$ sec

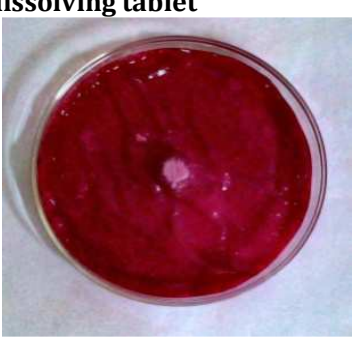

At Time $=103$ sec

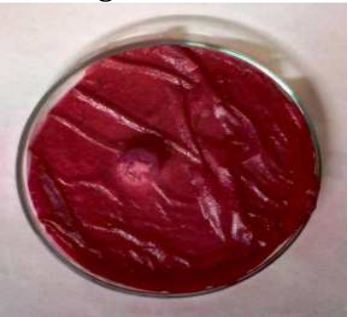

At Time $=90 \mathrm{sec}$

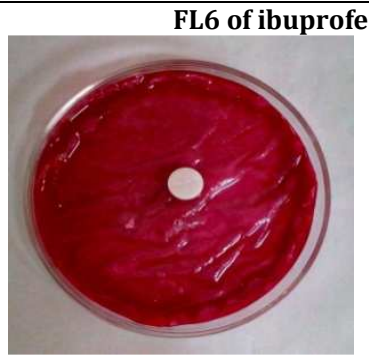

At Time $=0$ sec

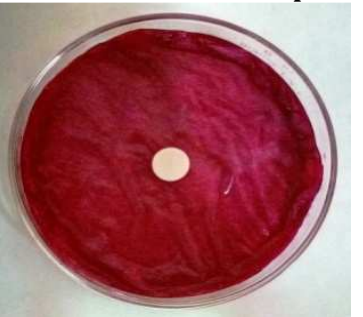

At Time $=0$ sec

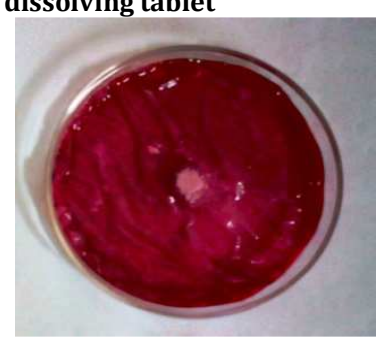

At Time $=183 \mathrm{sec}$

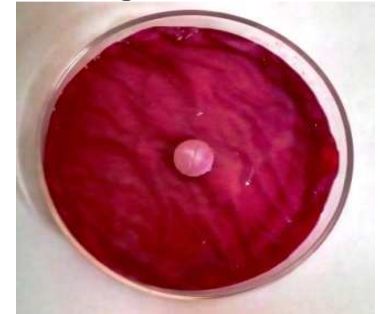

At Time $=369 \mathrm{sec}$

Fig. 8a: Ibuprofen fast dissolving tablets prepared employing starch xanthate involving lactose as a diluents 


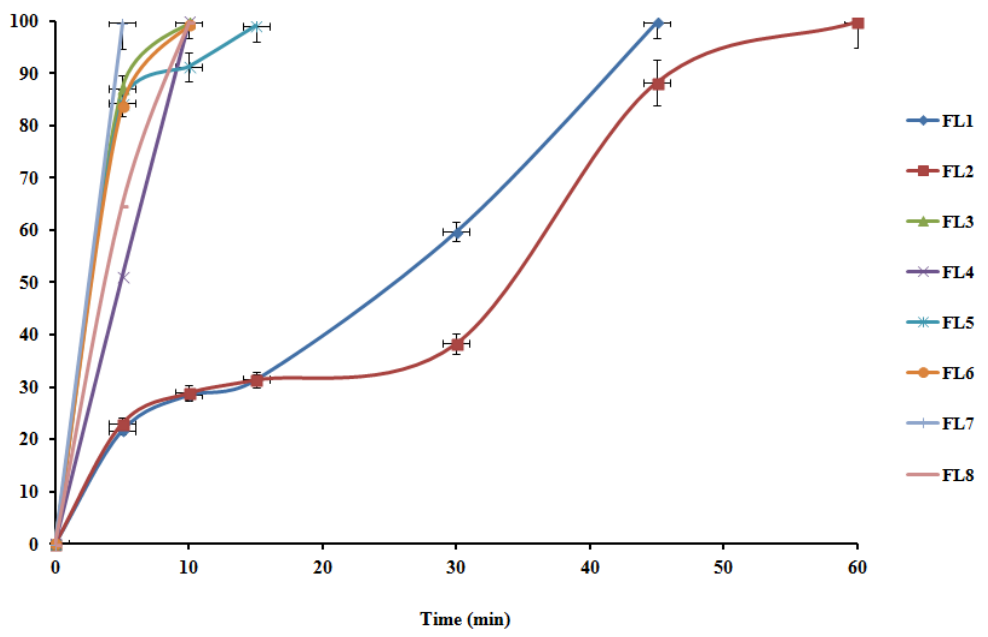

Fig. 9: Dissolution profiles of ibuprofen fast dissolving tablets prepared employing starch xanthate involving lactose as a diluents, (FL1FL8) $(n=6$, mean \pm SD)

Table 4: Dissolution parameters of ibuprofen fast dissolving tablets formulated employing starch xanthate and other known super disintegrants prepared by direct compression method involving lactose as a diluent

\begin{tabular}{|c|c|c|c|c|c|c|c|c|}
\hline Dissolution parameters* & FL1 & FL2 & FL3 & FL4 & FL5 & FL6 & FL7 & FL8 \\
\hline $\mathrm{PD}_{5}$ & 21.65 & 22.97 & 87.13 & 51.08 & 84.33 & 83.78 & 99.63 & 64.82 \\
\hline $\mathrm{DE}_{5} \%$ & 4.7 & 8.2 & 41.3 & 22.4 & 40.6 & 38.9 & 48.3 & 2.7 \\
\hline No of folds increase in $\mathrm{DE}_{5} \%$ & - & 1.74 & 8.78 & 4.76 & 8.63 & 8.27 & 10.27 & 4.82 \\
\hline $\mathrm{K}_{1}\left(\min ^{-1}\right)$ & 0.01 & 0.04 & 0.39 & 0.25 & 0.26 & 0.41 & - & 0.21 \\
\hline No of folds increase in $\mathrm{K}_{1}\left(\mathrm{~min}^{-1}\right)$ & - & 4 & 39 & 25 & 26 & 41 & - & 21 \\
\hline
\end{tabular}

*SD Standard Deviation from mean, n=3, $\mathrm{PD}_{5}$-Percent dissolved in 5 min., DE $\%$-Dissolution efficiency in 5 min., $\mathrm{K}_{1}=$ First Order Rate Constant

Table 5: ANOVA of dissolution efficiency in 5 min of ibuprofen fast dissolving tablets formulated employing starch xanthate involving lactose as a diluent

\begin{tabular}{|c|c|c|c|c|c|}
\hline Source of variation & d. $f$ & S. S & M. S. S & Variance ratio & Result \\
\hline Replicates & 2 & 0.81 & 0.40 & 0.50 & $\mathrm{P}>0.05$ \\
\hline Treatments & 7 & 5563.31 & 794.75 & 1006.01 & $\mathrm{P}<0.05$ \\
\hline Starch xanthate $(5 \%)$ & 1 & 25421.55 & 25421.55 & 32179.17 & $\mathrm{P}<0.05$ \\
\hline Strach xanthate $(10 \%)$ & 1 & 33.37 & 33.37 & 42.24 & $\mathrm{P}<0.05$ \\
\hline Starch xanthate $(5 \%) X$ Sodium starch glycolate $(5 \%)$ & 1 & 2137.59 & 2137.59 & 2705.81 & $\mathrm{P}<0.05$ \\
\hline Starch xanthate $(10 \%)$ X Sodium starch glycolate $(5 \%)$ & 1 & 62.72 & 62.72 & 79.39 & $\mathrm{P}<0.05$ \\
\hline Starch xanthate(5\%) X Croscarmellose sodium (5\%) & 1 & 4306.76 & 4306.76 & 5451.59 & $\mathrm{P}<0.05$ \\
\hline Starch xanthate $(10 \%)$ X Croscarmellose sodium (5\%) & 1 & 171.20 & 171.20 & 216.70 & $\mathrm{P}<0.05$ \\
\hline Starch xanthate $(5 \%)$ X Sodium starch glycolate $(5 \%)$ X Croscarmellose sodium $(5 \%)$ & 1 & 250.26 & 250.26 & 316.78 & $\mathrm{P}<0.05$ \\
\hline Starch xanthate $(10 \%)$ X Sodium starch glycolate(5\%) Croscarmellose sodium X (5\%) & 1 & 385.60 & 385.60 & 488.10 & $\mathrm{P}<0.05$ \\
\hline Error & 14 & 11.12 & 0.79 & -- & -- \\
\hline Total & 23 & -- & -- & -- & -- \\
\hline
\end{tabular}

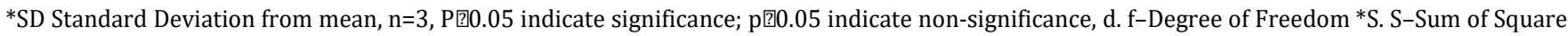
*M. S. S-Mean Sum of Squares, ANOVA= Analysis of Variance

\section{CONCLUSION}

Starch xanthate is an efficient super disintegrant for fast dissolving tablets. The disintegration and dissolution efficiency of the fast dissolving tablets of Ibuprofen was good and depended on the concentration of super disintegrant employed i.e., starch xanthate, sodium starch glycolate, croscarmellose sodium. The formulated fast dissolving tablets of Ibuprofen exhibited good dissolution efficiency in $5 \mathrm{~min}$ which can be used for the fast therapeutic action of ibuprofen.

Overall, Starch xanthate was found to be a super-disintegrant which enhanced the dissolution efficiency when combined with sodium starch glycolate and croscarmellose sodium, with the ibuprofen and hence it could be used in the formulation of fast dissolving tablets to provide immediate release of the contained drug within $5 \mathrm{~min}$.

\section{ABBREVIATION}

FTIR-Fourier transform infrared spectra, DSC-Differential scanning calorimetry, ANOVA-Analysis of variance, $\mathrm{PD}_{5}$-Percent dissolved in 5 min, $\mathrm{DE}_{5} \%$-Dissolution efficiency in $5 \mathrm{~min}$

\section{CONFLICT OF INTERESTS}

Declare none

\section{REFERENCES}

1. Amrita Soni, Vaibhav Rajoriya, Varsha Kashaw. Formulation development and evaluation of fast dissolving tablet of ramipril. Int J Pharm Pharm Sci 2015;7:127-31.

2. Paramita Dey, Arnabi Ghosh. Wafers: an innovative advancement of orodispersible films. Int J Appl Pharm 2016;8:1-7. 
3. Abdelbary G, Prinderre P, Couani C, Taochim J, Reynier JP, Riccerelle $\mathrm{P}$. The preparation of orally disintegrating tablets using a hydrophilic waxy binder. Int J Pharm 2004;278:423-33.

4. Anupam Roy. Orodispersible tablets: a review. Asian J Pharma Clin Res 2016;9:19-26.

5. Ashish Masih, Amar Kumar, Shivam Singh, Ajay Kumar Tiwari. Fast dissolving tablets: a review. Int J Cur Pharm Res 2017;9:8-18.

6. Biradar S, Bhagavati S, Kuppasad I. Fast dissolving drug delivery system: a brief overview. Int J Pharmacol 2005;4:2, 233-5.

7. Indurwade NH, Rajyaguru TH, Nakhat PD. Noval approach-fast dissolving tablets. Ind Drug 2002;38:405-9.

8. The United States Pharmacopoeia 29, National Formulary 24, Asian Edition. Rockville, MD: USPC, Inc; 2006. p. 1890.

9. Jacob S, Shirwaikar A, Joseph A, Srinivasan KK. Novel coprocessed excipient of mannitol and microcrystalline callous for preparing fast dissolving tablet of Glipizide. Ind J Pharm Sci 2007:69:633-9.

10. Hiremath JG, Shastry CS, Srinath MS. Pharmaceutical approaches of taste masking in oral dorage forms. Ind Drug 2004;41:253-7.

11. Abdelbary A, Elshafeey AH, Zidan G. Comparative effects of different cellulosic-based directly compressed orodispersible tablets on oral bioavailability of famotidine. Car Poly 2009;77:799-806.

12. Battu SK, Michael AR, Soumyajit M, Madhusudan Y Formulation and evaluation of rapidly disintegrating fenoverine tablets: effect of super disintegrants. Drug Dev Ind Pharm 2007;33:1225-32.

13. Goel H, Vora N, Rana V. A novel approach to optimize and formulate fast disintegrating tablets for nausea and vomiting. AAPS PharmSciTech 2008;9:774-8.

14. Satheesh Jogala, Laxman Ankathi, Ramesh Naik Jarupula. Glimepiride fast disintegrating tablets: formulation, evaluation and in vivo disintegration and dynamic studies. Int J Pharm Pharm Sci 2016;8:271-8.

15. Indian Pharmacopoeia 2010. p. 218-20.

16. V Sai Kishore, D Gowtham Kumar, B Sudheer, M Sandeep. Design and development of fast dissolving tablets of ibuprofen. Res Rev Pharm Pharm Sci 2013;2:65-71.

\section{How to cite this article}

- $\quad$ R Santosh Kumar, T Naga Satya Yagnesh, V Goutham Kumar. Optimisation of ibuprofen fast dissolving tablets employing starch xanthate using $2^{3}$ factorial design. Int J Appl Pharm 2017;9(5):51-59. 